\title{
As dimensões ensináveis do gênero textual "a comunicação oral em eventos cientificos"
}

The teaching dimensions of the textual gender "oral communication in scientific events"

Juliana Bacan Zani

Universidade São Francisco - USF

Luzia Bueno

Universidade São Francisco - USF

Joaquim Dolz

Universidade de Genebra - Suíça

DOI: https://doi.org/10.5902/2176148542386

\begin{abstract}
Resumo: Este artigo tem como objetivo apresentar as dimensões ensináveis do gênero “a comunicação oral em eventos científicos", de modo a possibilitar aos professores de nível superior desenvolverem diferentes atividades, ou até mesmo sequências didáticas para ensinar os alunos a produzirem esse gênero de texto. Baseamo-nos no quadro teórico metodológico do Interacionismo Sociodiscursivo - ISD (BRONCKART, 1999/2009, 2006, 2008 , 2013) e na complementação do quadro, por nós realizada, tanto para as questões do texto falado e os marcadores conversacionais, quanto para os aspectos não-verbais para realizar nossas análises e nos apoiamos no modelo didático do gênero exposição oral, elaborado por Schneuwly e Dolz (2004). A caracterização e a modelização didática desse gênero acadêmico oral e multimodal, baseado no quadro teórico metodológico do ISD, permite estabelecer uma matriz das dimensões regulares do gênero que merecem ser abordadas na formação universitária.
\end{abstract}

Palavras-Chave: Gênero textual oral. Modelo didático. Letramento acadêmico.

Abstract: This article has as aim to show the teachable dimensions of the genre "The oral communication in scientific events", in order to enable higher teachers to develop in different activities, or even, teaching sequences to instruct the students to produce this text genre. We are based in the theory methodological board of the sociodiscursive interactionism - ISD (BRONCKART, 1999/2009, 2006, 2008, 2013), and, in the board complementation, which has made for us, for the spoken text questions, for the conventional markers, and for the aspects non verbal to make ours analysis, we use as 


\section{Juliana Bacan}

Zani

Luzia Bueno

Joaquim Dolz

350 base the didactic modal of genre oral exposition, which was elaborated by Schneuwly and Dolz (2004). The characterization and the didactic modeling of this oral academic genre and multi-modal, were based in the methodological theory board of ISD, permits to set a regular matrix of dimensions of the genre, which deserve to be developed during the university education.

Keywords: Oral textual genre. Didactic model. Academic literacy

\section{Introdução}

As pesquisas sobre a oralidade vêm aumentando significativamente nas últimas décadas, conforme nos aponta Magalhães (2018), e os trabalhos sobre os gêneros orais também passam a ocupar um espaço importante. Contudo, ainda é forte o foco no ensino na educação básica e fraca a produção que vise "à formação de professores para o trabalho com gêneros orais, superando a constatação de que há lacunas na formação teórica e dificuldades materiais" (MAGALHÃES, 2018, p. 32).

No intuito de contribuir para alterar esse quadro, o presente artigo tem como objetivo apresentar as dimensões ensináveis do gênero “a comunicação oral em eventos científicos", de modo a possibilitar aos professores de nível superior desenvolverem diferentes atividades, ou até mesmo sequências didáticas ${ }^{1}$ para ensinar os alunos a produzirem esse gênero de texto. $O$ interesse pela temática surgiu devido às dificuldades que observamos nos alunos ao produzirem diferentes gêneros textuais que circulam na esfera acadêmica (escritos e orais), sendo necessário ensiná-los. Logo, nosso propósito é, também, contribuir para o Letramento Acadêmico.

Partimos, neste artigo, da perspectiva de Lea e Street (2014), para o letramento acadêmico. Para Lea e Street (2014), é preciso ter clareza de que, ao trabalhar com letramento na universidade, estão presentes relações de poder, de autoridade e de identidade, que geram tensões, conflitos, disputas. Assim, ensinar um gênero significa suscitar a posição que ganha quem o produz na universidade e, ao mesmo tempo, perceber que a aprendizagem dele pode ser bastante tensa para aprendiz, pois pode implicar modos de agir, falar, portar-se muito diferente do que o aluno já conhece (ZAVALA, 2010). Além

1 Tomamos o conceito de sequência didática como um conjunto de atividades organizadas, de maneira sistemática, em torno de um gênero de texto, possibilitando o desenvolvimento das capacidades necessárias para que os alunos dominem um determinado gênero. 
disso, nesta perspectiva, descarta-se a teoria do déficit do aluno, isto é, de que o desconhecimento de gêneros textuais ou dos modos de agir na universidade seriam responsabilidade do aluno. Defendemos a proposta de que a universidade (e cada curso em particular), enquanto uma esfera de atividade, precisa trabalhar com os textos e os modos de agir que são importantes tanto para o sucesso acadêmico quanto a formação profissional.

E a comunicação oral em eventos científicos é uma das práticas que vivenciamos nessa esfera acadêmica, sem, na maior parte dos casos, ter tido a chance de aprender primeiro a fazê-la. Mas que gênero é este? Partimos de bases da exposição oral, do seminário, mas existem particularidades específicas para este gênero. Quais são? Como identificá-las? É o que pretendemos fazer neste artigo.

As dimensões

ensináveis do gênero textual " $a$ comunicação oral em eventos científicos"

Para apresentar a nossa proposta, organizamos o nosso artigo em cinco seções. Na primeira seção, trazemos as discussões sobre o processo de ensino-aprendizagem por meio dos gêneros textuais. Em seguida, na segunda seção, apresentamos as questões metodológicas para a elaboração do modelo didático. Na terceira seção, definimos e contextualizamos o termo "comunicação oral", que se fez necessário ao logo do trabalho. Para depois, na quarta seção, apresentar as dimensões ensináveis do gênero, ou seja, o modelo didático do gênero (MDG). E por fim, na quinta seção, faremos as nossas considerações finais.

\section{Ensinar e aprender pelos gêneros textuais}

A abordagem que será apresentada neste artigo está ancorada nos trabalhos da equipe da Didática de Línguas da Faculdade de Psicologia e Ciências da Educação da Universidade de Genebra, cujos trabalhos tiveram início na década de 1980 com o objetivo de investigar questões relacionadas ao ensino de língua materna (francês).

Essa equipe, tendo como expoentes maiores os pesquisadores Jean-Paul Bronckart, Bernard Schneuwly, Joaquim Dolz e colaboradores, tem seus trabalhos voltados para dois campos: um mais direcionado para as questões epistemológicas do agir humano no discurso em diferentes situações de trabalho e outro mais voltado para as questões de didática de ensino, dedicando-se à elaboração de princípios e métodos do ensino do francês por meio do ensino-aprendizagem da produção de gêneros orais e escritos na aplicação e desenvolvimento de sequências didáticas. 
Este artigo se enquadra nos trabalhos voltados para as questões didáticas de ensino e, a partir de agora, nós nos limitaremos às discussões sobre o gênero no processo de ensino e aprendizagem. Para organizar nossas discussões, nesta seção, abordaremos um conceito mais amplo do gênero como ferramenta didática, destacando o seu papel como

Juliana Bacan

Zani

Luzia Bueno

Joaquim Dolz

352 objeto de ensino e aprendizagem da produção textual oral e escrita.

Retomando a tese de que o desenvolvimento do pensamento consciente humano se dá por meio da linguagem, mais precisamente, por meio de práticas linguageiras situadas e de que o ensino exerce um importante papel para o desenvolvimento humano (BRONCKART, 1999/2009), Schneuwly e Dolz (2004) propõem um ensino voltado a essas práticas de linguagem que se realizam em textos organizados em gêneros.

Sendo assim, o gênero é utilizado como intermediador entre as práticas sociais e os objetos escolares, principalmente em se tratando do ensino da produção de textos orais e escritos. Vale ressaltar que os autores tratam a noção de gênero não apenas como unidade de ensino, mas como uma ferramenta que tem a função de atuar no processo de ensino e aprendizagem.

Dolz e Gagnon (2015, p. 34) apresenta o termo "ferramenta" como referência ao meio cultural que é construído pelo homem para transformar a natureza, ou seja, o ser humano é "um animal fabricador de ferramentas", afirmam os autores baseando-se em Marx (1968).

No sentido vigotskiano, os humanos criam instrumentos técnicos (que possibilitam aos homens controlar o ambiente físico e social daqueles que ali interagem), e/ou instrumentos psicológicos. (que permitem regular tanto seus próprios comportamentos como dos outros. Os instrumentos técnicos poderão se tornar instrumentos psicológicas se forem apropriadas pelo sujeito, transformando as capacidades psíquicas de si mesmo ou dos outros, gerando assim, o desenvolvimento humano.

Dessa forma, seguindo a perspectiva do interacionismo social, conforme destacado por Schneuwly (2004a, p. 21), a atividade humana é concebida como tripolar, pois 1) a ação dos sujeitos sobre a natureza é mediatizada por objetos específicos, socialmente construídos e frutos de experiências anteriores, os quais são chamados por Rabardel (1993) de "artefato material ou simbólico"; 2) os instrumentos, que se encontram entre o sujeito que age e o objeto ou a situação sobre qual ele age, 
considerados por Vigotski (1934/1985) de instrumento psicológico; e, 3) a ação do próprio sujeito ao apropriar-se desses instrumentos, possibilitando mudanças em seu comportamento numa determinada situação.

Seguindo a proposição de Rabardel (1993), o instrumento pode ser considerado como um artefato material ou simbólico que existe fora do sujeito, entretanto, a partir do momento em que este artefato é apropriado, ele passa a ser um verdadeiro instrumento. Para o autor, o instrumento só se torna mediador na atividade humana, quando é apropriado pelo sujeito. Machado e Lousada (2010, p. 626) consideram que "apropriar-se de alguma coisa é adaptar alguma coisa a um uso ou a uma finalidade determinada, fazendo com que ela seja sua" (grifo nosso). Desse modo, quando um artefato é apropriado pelo sujeito, ele passa a ser o verdadeiro instrumento psicológico.

As dimensões

ensináveis do gênero textual " $a$ comunicação oral em eventos científicos"

Os gêneros, mediadores da atividade humana, associados às esferas das atividades específicas, conforme Dolz e Gagnon (2015, p. 35) "são vistos como ferramentas devido ao fato de que, atuando em situações linguageiras, cujas possibilidades de desenvolvimento se atualizam, sendo apropriadas no uso". Nesse sentido e a título de exemplo a pesquisa de Wirthner (2017) mostra como o uso das sequências didáticas, nova ferramenta de trabalho para os professores, modifica a atividade docente e joga um rol formador e transformador das práticas.

Neste trabalho, postulamos que o ensino de gêneros atuará no espaço entre o que o aluno ainda não sabe sobre o gênero e onde ele pode chegar. Vigotski (1985) nomeia esse espaço de Zona de Desenvolvimento Proximal (ZPD), conceito que utiliza para o espaço criado entre a distância daquilo que o aluno é capaz de fazer sozinho, sem ajuda, e o que consegue realizar com a colaboração de outro ou de uma ferramenta. Logo, alunos, professores e objeto ou ferramenta de ensino devem estar em constante interação para que os objetivos da aprendizagem possam ser alcançados. O gênero, quando se torna ferramenta de ensino e aprendizagem, permite, também, o desenvolvimento de capacidades de linguagem nas pessoas, ou seja, a capacidade de agir com a linguagem em diferentes práticas sociais.

Essas capacidades de linguagem envolvidas na produção de um texto se dividem em três: a) a capacidade de ação, que se refere à mobilização das características do contexto de produção, percebendo em que situação de comunicação um texto de um dado gênero pode ser produzido, por quem o produziu, para quem, com que objetivo, onde, em que 
Juliana Bacan

Zani

Luzia Bueno

Joaquim Dolz

momento e a que se refere; b) a capacidade discursiva, que diz respeito à percepção do modo como o texto foi organizado, ou seja, à infraestrutura geral do texto; e c) a capacidade linguístico-discursiva, que se reporta ao domínio dos recursos linguísticos utilizados adequadamente no contexto de produção de um determinado gênero.

As capacidades de linguagem funcionam de forma articulada e interligada, contribuindo, assim, para a apropriação de um gênero textual escrito ou oral de forma global. A análise e a observação dessas capacidades, antes e durante o processo de ensino, permitem a realização de uma intervenção didática mais precisa por parte do professor, a fim de mobilizar os conhecimentos que os aprendizes ainda não tenham e que possam ir adquirindo durante o processo.

Sob essa perspectiva, ao introduzir o ensino dos gêneros textuais, sejam escritos ou orais, na escola ou universidade, é preciso compreendê-los como um "objeto e instrumento de trabalho para o desenvolvimento da linguagem" (SCHNEUWLY e DOLZ, 2004, p. 6869). Não se trata do ensino do gênero pelo gênero, mas de "aprender a dominar o gênero, primeiramente, para melhor conhecê-lo, para melhor compreendê-lo, para melhor produzi-lo na escola ou fora dela", e também de "desenvolver capacidades que ultrapassam o gênero e que são transferíveis para outros próximos ou distantes".

Sendo assim, esse desdobramento é que torna o ensino do gênero complexo e mais ainda, a dificuldade de escolher, dentre uma enorme variedade de gêneros, aqueles que podem tornar-se objeto de ensino, principalmente quando nos referimos aos gêneros orais, tema central deste trabalho.

Dolz e Gagnon (2015, p. 39) destacam que o gênero indica as dimensões a serem ensinadas (contexto de produção, arquitetura textual, mecanismos de textualização). Neste sentido, a elaboração de um modelo didático de um gênero, proposto por Dolz e Schneuwly (2004), pressupõe a identificação dessas dimensões ensináveis de um gênero, possibilitando, assim, desenvolver determinadas atividades e sequências de ensino.

O Modelo Didático de Gênero (doravante MDG) consiste em um estudo sistematizado com um número significativo de textos de um dado gênero, visando a conhecer suas características predominantes e formalizando as dimensões ensináveis dos gêneros textuais para o ensino. 
O modelo didático é "um objeto descritivo e operacional, construído para apreender o fenômeno complexo da aprendizagem de um gênero" (DE PIETRO, 1996/1997, p. 118), ou seja, a construção do mesmo possibilita conhecer as dimensões constitutivas do gênero e selecionar as que podem ser ensinadas e necessárias para um determinado grupo escolar. Assim, o MDG está estreitamente relacionado a um trabalho que propicie o desenvolvimento das capacidades de linguagem necessárias para a produção de textos escritos ou orais.

Para Schneuwly e Dolz (2004, p. 69), em um modelo didático, é preciso estar explícito o que é implícito em um gênero, ou seja, os saberes já existentes sobre o gênero (sobre o qual será construído o modelo), tanto no domínio da pesquisa científica quanto pelos profissionais especialistas. Os autores, ainda, acrescentam que o modelo didático deve ser As dimensões ensináveis do gênero textual " $a$ comunicação oral em eventos científicos" "uma síntese com objetivo prático, destinada a orientar as intervenções dos professores", devendo evidenciar as dimensões ensináveis de um gênero. (SCHNEUWLY e DOLZ, 2004, p.70).

A construção do MDG é essencial para ensinar e aprender pelos gêneros, pois este servirá de guia ao trabalho do professor, facilitando a visualização do que pode ser ensinado e aprendido nas práticas escolares. A partir desse modelo, é possível encontrar os elementos essenciais a serem ensinados, delimitar os objetivos a serem atingidos e identificar as capacidades de linguagem que os alunos já desenvolveram e aquelas que precisam ser desenvolvidas.

Com efeito, o MDG é uma ferramenta potencial para o ensino. É potencial, por um lado, "porque sua seleção deve ser feita em função das capacidades dos aprendizes" e por outro "porque não poderia se ensinar o modelo como tal", pois é por meio das atividades, das manipulações, que os aprendizes terão acesso aos gêneros modelizados. (DOLZ, SCHNEUWLY e HALLER, 2004, p. 152).

Logo, podemos destacar que o MDG é uma excelente "caixa de ferramentas", para o professor, pois existem diversas possibilidades de escolha, de acordo com a necessidade do seu grupo de alunos. Usamos a metáfora "caixa de ferramentas" pois o professor irá escolher a ferramenta necessária para realizar a sua atividade. Sendo assim, o MDG é flexível, podendo ser adaptado e reconstruído de acordo com o contexto escolar.

Essa ideia reforça o que já foi evidenciado por Machado e Cristóvão (2006), ou seja, que o modelo didático serve como um exemplo, um norteador para ensino e aprendizagem dos gêneros textuais, sendo 
apenas uma das etapas para a realização efetiva do ensino, considerando que o trabalho só funciona se o gênero não for tomado como um estereótipo único e imutável.

\section{A elaboração do Modelo Didático}

Juliana Bacan

Zani

Luzia Bueno

Joaquim Dolz

356

Começamos por recordar que, como exposto anteriormente, o MDG consiste em uma síntese com objetivo prático para orientar as intervenções dos professores, bem como mostrar as dimensões ensináveis, as quais servirão de base para a criação de sequências didáticas.

Dessa forma, a primeira etapa para construção do modelo didático foi buscar especialistas do gênero. Nessa fase, encontramos poucos estudos que se dedicavam aos gêneros orais e mais especificamente na comunicação oral em eventos científicos. Encontramos respaldo para modelizar o gênero nos trabalhos de Schneuwly e Dolz (2004), que já haviam investigado e proposto um modelo didático e uma sequência didática para a exposição oral - seminário -, e no modelo didático do gênero a arguição do candidato para qualificação ou defesa de mestrado e doutorado desenvolvido por nós (ZANI; BUENO, 2013).

Em seguida, buscamos vídeos, gravações de comunicações orais em eventos científicos, como vídeo de referência e muito pouco foi encontrado. Assim, foi necessário criar um banco de dados com vídeos de professores/pesquisadores os quais conhecemos e participam de um grupo maior desta pesquisa, grupo ALTER. Fizeram parte da nossa coleta de dados, três gravações em vídeo, de três professores/pesquisadores de programas de pós-graudação de diferentes regiões do nosso país, sendo estes, líderes de grupos de pesquisa e participantes ativos de eventos científicos.

Com o material coletado partimos para a investigação da nossa questão de pesquisa - "Que dimensões do Gênero Comunicação Oral em Eventos Científicos merecem ser ensinadas?" - a qual foi necessário dividi-la em subquestões: a) Quais são as características do gênero em relação ao contexto de produção e à infraestrutura textual?; b) Quais são as características do gênero em relação aos aspectos linguísticos-discursivos e paralinguísticos?

Para respondê-las, baseamo-nos no quadro teórico metodológico do Interacionismo Sociodiscursivo - ISD (BRONCKART, 1999/2009, $2006,2008,2013)$ e na complementação por nós realizada, tanto para as questões do texto falado e os marcadores conversacionais, quanto para os aspectos não-verbais. 
Partindo do Modelo Didático do Gênero Exposição Oral, elaborado por Schneuwly e Dolz (2004), do Modelo Didático da Arguição do Candidato de Mestrado ou Doutorado para qualificação ou defesa, elaborado por Zani; Bueno (2013), e dos vídeos de professores universitários que coletamos para o nosso banco de dados, inicialmente, analisamos o contexto de produção, ou seja, a situação de comunicação, considerando as representações do produtor e suas ações perante essas representações. Para isso, descrevemos a situação de produção (quem produz, para quem produz, com que objetivo, de que lugar comunicam etc.).

Após esse primeiro momento de investigação, analisamos a arquitetura textual, que consiste em conteúdo temático e planificação do gênero. Primeiramente centramos no conteúdo temático e seu desenAs dimensões ensináveis do gênero textual "a comunicação oral em eventos científicos" cadeamento. Em seguida, observamos a estruturação e planificação do gênero comunicação oral. Destacamos, também, os tipos de discurso, analisando a ordem composicional, construídas a partir das representações do produtor no momento da produção.

Posteriormente, pautamo-nos em uma análise dos mecanismos de textualização, isto é, as unidades linguísticas que iram aparecer no texto. Por isso, levamos em consideração a coerência temática dos textos produzidos a partir de uma análise dos processos de conexão, de coesão nominal e coesão verbal. Neste aspecto, de acordo com os autores, tratamos também das características do texto falado e do uso de marcadores conversacionais.

Por se tratar de um gênero oral, analisamos também os meios paralinguísticos, considerando a qualidade da voz, melodia, pausas, gestos corporais e faciais, postura corporal, troca de olhares entre outros, que são considerados como aspectos não-linguísticos. E por fim, investigamos a utilização e estruturação do suporte escrito, gênero de texto imbricado no gênero oral e que faz parte da Comunicação Oral em eventos científicos.

Durante o processo de análise, surgiu também a necessidade de definir o conceito de gênero de texto "a exposição oral", em uma comunicação oral em eventos científicos, que foi se delineando diferentemente da exposição oral em um seminário. Em suma, buscamos em outras leituras (artigos, dicionários e chamadas para submissões de comunicação em congressos) definições sobre o termo, que iremos explanar a seguir. 


\section{A comunicação oral em eventos científicos}

Para iniciarmos esta seção, começamos por definições e conceitos para “exposição" e "comunicação", que posteriormente nos ajudarão a justificar as escolhas dos termos pelos quais optamos no percurso desta pesquisa.

Juliana Bacan

Zani

Luzia Bueno

Joaquim Dolz

Dessa forma, em uma primeira busca pelo termo encontramos no dicionário as seguintes definições: "exposição - s.f. Ação de expor, de apresentar por escrito ou oralmente ideias ou fatos: exposição de uma teoria. Colocar à mostra obras de..." e "comunicação - s.f. o que se relaciona ou pode ocasionar a transmissão ou recepção de ideias ou de mensagens, buscando compartilhar..."

Dolz et al. (2004) definem a exposição oral como:

[...] um gênero textual público, relativamente formal e específico, no qual um expositor especialista dirige-se a um auditório, de maneira (explicitamente) estruturada, para lhe transmitir informações, descrever-lhe ou lhe explicar alguma coisa (DOLZ et al. 2004, p. 218).

Para os autores, a exposição oral é um discurso realizável em uma situação comunicativa específica, o qual eles denominam de bipolar, “que reúne o orador/expositor e seu auditório, e se concretiza em um espaço-tempo de produção onde o expositor se endereça ao destinatário por meio de uma ação linguageira vinculada a um conteúdo referencial. " (DOLZ, 1998 - tradução nossa²)

Assim, a exposição oral é muito utilizada nas escolas e até mesmo nas universidades, cujo objetivo maior é obedecer a uma estrutura convencionalizada de aprendizagem, na qual um aluno se apropria, por um determinado tempo, do lugar do professor, para transmitir um tema (geralmente escolhido pelo professor), aos demais colegas da turma.

Esse gênero é mais conhecido como gênero "seminário" e aparece como proposta de trabalho para alguns níveis de escolaridade do Ensino Fundamental 1 e 2, como proposta de ensino de um gênero oral

2 L'exposé est un discours qui se réalise dans une situation de communication spécifique qu'on pourrait appeler bipolaire, réunissant l'orateur ou l'exposant et son auditoire. L'exposé pourrait ainsi être qualifié, en suivant Bronckart et al. (1985), comme un espace-temps de production où l'énonciateur s'adresse au destinataire par l'intermédiaire d'une action langagière véhiculant un contenu référentiel. (DOLZ, 1998, p. 142) 
e, principalmente, para o Ensino Médio e Superior, embora permaneça como uma atividade tradicional, na qual o aluno expõe perante a turma seus conhecimentos sobre um determinado assunto, sem que nenhum trabalho didático anterior tenha sido explorado pelo professor, permitindo ao aluno a construção da linguagem expositiva.

Em contrapartida, atualmente, encontramos na sociedade científica e acadêmica diversos eventos que são promovidos por diferentes instituições, com o objetivo de oportunizar o contato entre os pares, sistematizar os avanços em uma determinada área do saber, divulgar novos conhecimentos e traçar metas para futuros empreendimentos.

As pessoas interessadas em participar dos eventos submetem seus trabalhos, de acordo com as normas e prazos estabelecidos pela organização, os quais, após apreciação e aprovação por comissões de

As dimensões ensináveis do gênero textual " $a$ comunicação oral em eventos cientificos" especialistas, são expostos por meio de uma das modalidades básicas de apresentação: a comunicação oral, que possibilita aos participantes divulgar seu trabalho, receber apreciações, sugestões e críticas, além de possibilitar a ampliação do rol de interlocutores.

Sendo assim, a exposição oral é utilizada como uma modalidade de divulgação científica, realizada por meio da exposição verbal, de tempo variável, com ou sem o auxílio de recursos multimodais, cuja duração é estipulada pelas comissões organizadoras dos eventos científicos, seguida de breve debate e pedidos de esclarecimento. Sua finalidade é relatar sucintamente um estudo (em andamento ou finalizado), indicando os aspectos mais relevantes do mesmo, sendo: considerações iniciais e objetivos do estudo, a metodologia empregada, os principais resultados obtidos, a discussão dos resultados e considerações finais.

Logo, adotamos o termo "comunicação oral" por ser mais próximo ao nosso contexto de produção, pois é um gênero de texto que circula na esfera acadêmica e científica e que, nas diversas propostas de exposição oral em congressos, seminários, simpósios, entre outros, as nomeiam assim. Algumas características do gênero se assemelham com o que temos encontrado até o momento sobre a exposição oral. Portanto, o que definimos aqui é a terminologia que estaremos utilizando.

Considerando esse quadro teórico e a definição do termo adotado, partimos para as discussões sobre as características gerais do gênero comunicação oral em eventos científicos, ou seja, as dimensões ensináveis do gênero. 


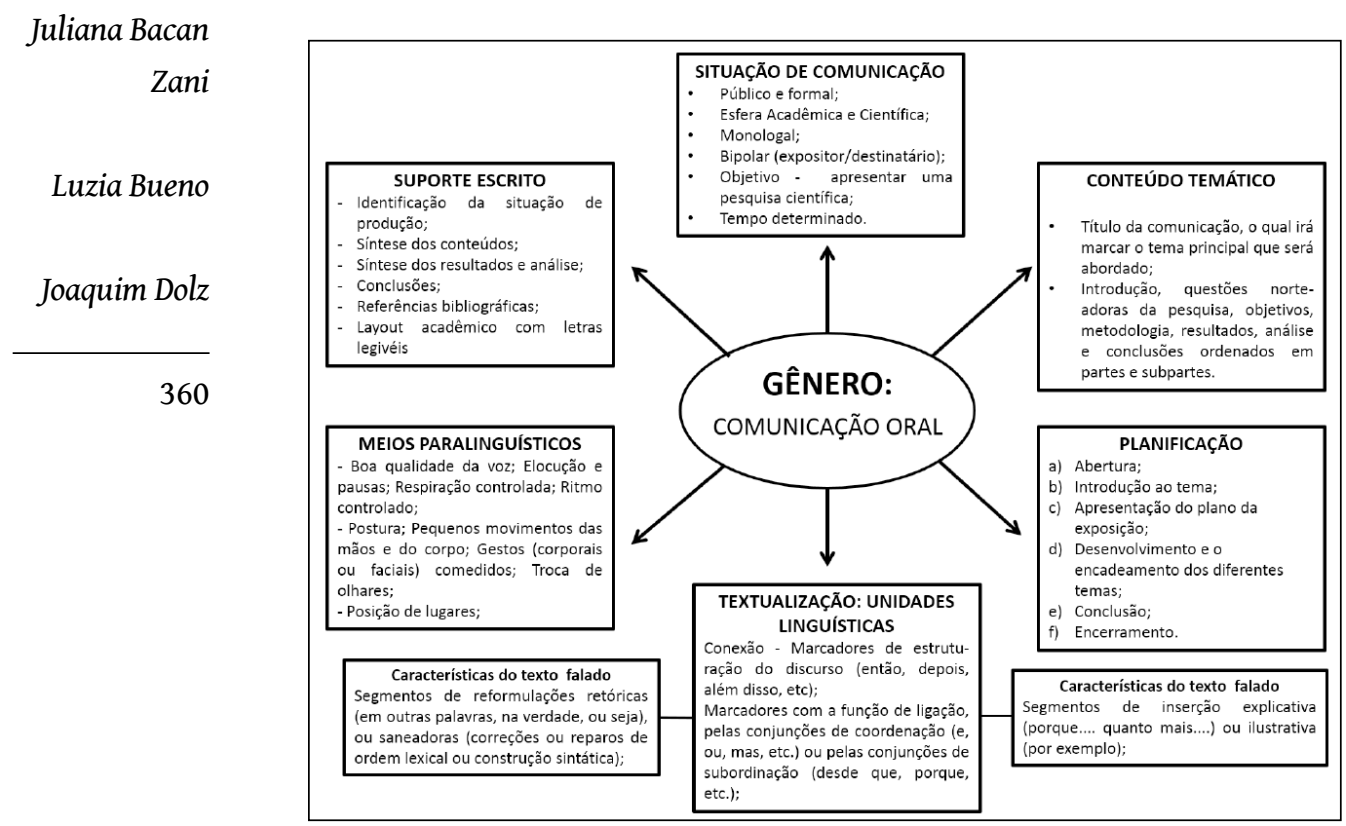

\section{As dimensões ensináveis do gênero comunicação oral em eventos científicos}

Com os resultados obtidos em nossas análises, organizamos uma figura síntese do modelo didático do gênero "comunicação oral em eventos científicos", que apresentamos a seguir.

FIGURA 1 - Modelo didático do gênero “Comunicação Oral em Eventos Científicos

\section{Situação de comunicação}

Conforme exposto anteriormente, a comunicação oral em eventos científicos é um gênero formal, concretizado na esfera acadêmica e científica. É uma situação de comunicação que reúne: um expositor/ pesquisador, que terá um tempo determinado para expor seu trabalho; $\mathrm{e}$ um público/receptor, ou seja, os interlocutores, que estão ali presentes por interesse na temática, ou porque também irão apresentar uma comunicação cujos temas podem ser comuns, ou somente estão ali para aprender algo. Além disso, temos um coordenador da seção de comunicações que assume, também, o papel de receptor, mas que terá a função de conduzir e promover as discussões ao final das seções.

Podemos então destacar que temos um expositor/pesquisador, que assume um papel de especialista, ou seja, um expert da temática e os receptores, que representam diferentes papéis sociais, sendo: de coordenadores, professores, pesquisadores, alunos, entre outros. 
O objetivo da comunicação oral é divulgar os conhecimentos produzidos ou a serem produzidos na realização da pesquisa, para depois debaterem e construírem novos conhecimentos, contribuindo assim para as comunidades acadêmicas e científicas. Logo, o expositor precisa levar em conta o conhecimento do destinatário, as expectativas, ou seja, o que se espera dentro da temática proposta, tentando manter a atenção do público com estratégias discursivas e oratórias. Logo, o tipo de evento que o comunicador irá apresentar e o público que estará presente ajudarão a nortear a comunicação oral.

Sendo assim, é preciso ter uma boa organização do conteúdo e a planificação do texto, ou seja, da comunicação oral que será apresentada.

\section{Conteúdo temático}

As dimensões

ensináveis

do gênero

textual " $a$ comunicação oral em eventos cientificos"

Partindo do eixo temático a ser apresentado na comunicação oral, é preciso escolher um título para o trabalho e os temas e subtemas a serem desenvolvidos na apresentação, de maneira clara e compreensível para o público a quem se dirige. É o momento de se questionar e levar em consideração a situação de comunicação, ou seja, levar em conta o que se sabe sobre o público e o tempo disponível para expor as ideias.

Essa fase de questionamentos possibilita a definição dos objetivos a serem alcançados, a delimitação do tema a ser abordado, a seleção do conteúdo de forma sucessiva e o agrupamento de ideias de modo coerente, que facilitarão a compreensão da temática para os ouvintes (público).

A preparação de uma comunicação oral implica na escolha de informação com argumentos que mostram a ideia principal e, por tratar de conteúdos relacionados a um tema de uma pesquisa acadêmica/ científica, é preciso:

- fazer uma introdução da temática, partindo da problemática do tema abordado, das questões norteadoras para se chegar ao objetivo do trabalho, ou seja, da pesquisa. Aqui é um dos pontos que nos chama a atenção e sentimos a necessidade de fazer uma breve reflexão. Apresentar o objetivo da pesquisa que está em andamento ou já foi finalizada não é o mesmo que apresentar o objetivo da comunicação. Essa é uma das confusões que temos encontrado em diferentes situações.

- apresentar o percurso metodológico traçado no estudo de forma clara e direta, sem necessidade de pormenorizar as fases ou etapas da coleta de dados, a não ser que determinados detalhes sejam indispensáveis à compreensão e análise dos dados. 
Juliana Bacan

Zani

Luzia Bueno

Joaquim Dolz

- fazer uma descrição dos principais dados obtidos no estudo e interpretá-los, retomando os objetivos centrais e comparando os dados com a fundamentação teórica da área.

- enfatizar a contribuição da pesquisa, dando indicações quanto à continuação do estudo a partir das prováveis lacunas que não foram preenchidas, fazendo assim as considerações finais do trabalho.

\section{Planificação}

A planificação de um texto é a construção de um plano e elaboração de uma rede de propósitos, ou seja, uma organização interna de uma apresentação. Dolz e Schneuwly (1998) propõem algumas fases para a organização da comunicação oral:

a) Abertura - momento em que o expositor-especialista tem o primeiro contato com o público, saúda-o, legitimando a sua fala;

b) Introdução ao tema - o expositor-especialista irá apresentar o título do seu trabalho/pesquisa, o ponto de vista adotado e as delimitações do assunto a ser apresentado. Esta fase é considerada importante para instigar no ouvinte a atenção, o interesse e a curiosidade sobre o assunto que será exposto;

c) Apresentação do plano da exposição - momento em que o expositor apresenta o objetivo da comunicação, enumerando as ideias ou subtemas que serão tratados, tornando-se, assim, transparente e explícito o plano da apresentação, tanto para o público ali presente como para o próprio expositor. Nesta etapa, é importante apresentar as principais ideias que serão discutidas ao logo da comunicação;

d) Desenvolvimento e o encadeamento dos diferentes temas - consiste no encadeamento dos diferentes subtemas decorrentes do desdobramento do assunto a ser tratado. No gênero em questão, inclui-se a apresentação da Fundamentação Teórica, Metodologia, Análise dos Dados e Resultados;

e) Conclusão - momento em que o expositor-especialista transmite um parecer final sobre as questões tratadas na exposição, podendo ser desencadeado um problema novo ou ocorrer o início de um debate;

f) Encerramento - etapa em que o expositor finaliza a exposição e agradece a atenção do auditório. 
Ainda dentro da planificação do texto, é preciso evidenciar que tipo de relação o expositor irá estabelecer com o seu público, ou seja, quais são os tipos de discursos mobilizados. Um discurso interativo cuja intenção do expositor não é só trazer uma relação de simultaneidade entre as ações e a enunciação, mas também de aproximar o público as suas experiências e ao percurso da sua pesquisa. Ou um discurso teórico - momento em que o expositor não se coloca na ação.

\section{Textualização: unidades linguísticas}

A utilização de uma linguagem clara, objetiva, adequada à norma culta $\mathrm{e}$ permeada da terminologia própria da área de conhecimento à qual vincula-se o trabalho é de extrema importância. Não é necessária uma formalidade exagerada, porém suficientemente correta, apresentando um domínio razoável do conteúdo e da terminologia da sua área de atuação.

Nesta etapa, conforme Dolz e Schneuwly (1998), é preciso construir as operações linguísticas específicas do gênero em questão, possibilitando, assim, o desenvolvimento de competências metalinguísticas e em particular a capacidade de explicitar a estrutura da exposição, demarcando os níveis de progressão e de estruturação do discurso.

Dessa forma, é preciso estar atento à conexão entre as frases que compõem o texto, apresentando, assim, os marcadores de estruturação do discurso, que podem ser explícitos por advérbios ou locuções adverbiais (então, depois, além disso, etc.) ou por sintagmas preposicionais com função de a) adjunto adverbial (depois de um bom tempo); b) estruturas adjuntas (para apresentar esse estudo); os marcadores com a função de ligação, sinalizados pelas conjunções de coordenação (e, ou, mas, etc.) ou pelas conjunções de subordinação (desde que, porque, etc.); e os articuladores que distinguem as ideias principais das secundárias (sobretudo).

Outro ponto a ser considerado é em relação à coesão nominal, pois o uso de anáforas nominais e pronominais e até mesmo as elipses contribuem para um texto mais claro e sem muitas repetições.

Nas comunicações orais é preciso também estar atento às características do texto falado, ou seja, utilizar-se de segmentos de inserção explicativa (porque.... quanto mais....) ou ilustrativa (por exemplo, para exemplificar, tomamos como exemplo); ou de segmentos de reformulações retóricas, que buscam reformular uma ideia e tornar mais fácil o entendimento do que se está querendo dizer (em outras palavras, na 


\section{Juliana Bacan}

Zani

Luzia Bueno

Joaquim Dolz

364 verdade, ou seja), ou saneadoras, com a função de correções ou reparos de ordem lexical ou construção sintática (neste aspecto apre/, perdão, destacamos .....; nesta perspectiva destaco / destacamos que....).

Vale ressaltar, ainda, que o uso de marcadores conversacionais (né, é, tá, entre outros) ou hesitações (eh, ah, ih) se faz muito presente na comunicação oral, e muitas vezes de forma espontânea, entretanto precisa ser utilizado de forma comedida, pois, em excesso, pode empobrecer a apresentação e deixar uma impressão negativa na audiência.

\section{Meios paralinguísticos}

Nos meios paralinguísticos, encontramos os elementos prosódicos que são conhecidos por meio da respiração, ritmo e entonação. Esses aspectos são inseparáveis da fala, pois dão a direção da mensagem durante a comunicação oral.

O ritmo da fala e sua entonação é extremamente importante e dará vida à comunicação. Ritmo e entonação produzem efeitos sonoros que podem atingir diretamente o público.

O importante é considerar que as variações de tom permitem o alívio à fala. As várias entonações da voz durante a apresentação é um meio de gerar interesse ou enfado. Logo, variar os estímulos permite manter a atenção do público. Ronveaux (1996/97) destaca que um bom orador joga habitualmente com os elementos melódicos, sendo: o volume, o tom, o ritmo, o tempo.

Outro aspecto a ser considerado nos elementos paralinguísticos são os meios cinésicos. Em qualquer situação de comunicação, o corpo também fala, dando vida à apresentação. Sendo assim, a postura, os gestos (corporais ou faciais), a troca de olhares são elementos que buscam interação com o público.

O gesto está sempre presente e complementa a comunicação. Entretanto, é preciso utilizá-lo de forma comedida, pois em excesso pode atrapalhar e/ou confundir o público. Um exemplo clássico é a utilização das mãos, que sempre é utilizada, porém, podem roubar a cena se não tiver o controle.

Em relação à troca de olhares, Knapp (1999, p, 297) destaca que “o contato visual ocorre quando queremos assinalar que o canal de comunicação está aberto", apontando cinco funções do olhar: 1) regular o fluxo de comunicação; 2) monitorar o feedback; 3) refletir a atividade cognitiva; 4) expressar emoções; 5) comunicar a natureza da relação interpessoal. 
Estabelecer um contato visual direto com o público permite manter uma relação mais próxima, ganhando sua atenção. Quando o nosso olhar fixa para o teto ou fundo do auditório, ou para as anotações ou material visual (PowerPoint), corremos o risco de perder a atenção do público ali presente.

E, por fim, em relação à posição dos locutores, é preciso estar atento à ocupação de lugares. 0 expositor deve ficar à frente da sala, de maneira que não dê as costas e que não atrapalhe a visão do público, principalmente, quando há utilização de recursos visuais (PowerPoint).

\section{Suporte}

Durante uma seção de comunicação oral, é bastante comum e até esperado que o expositor utilize recursos visuais e/ou audiovisuais para facilitar sua comunicação com o público. Dentre os recursos mais utilizados temos, hoje, o projetor multimídia (Datashow).

Esse suporte serve tanto para o próprio expositor, que irá ajudá-lo no desenvolvimento e progressão do tema a ser tratado e quanto para o público presente. A utilização desse suporte também precisa ser planejada e seguir alguns critérios, como:

1) Registrar as palavras ou as expressões fundamentais que evocam determinados conteúdos, mencionando, para cada etapa, a ideia principal, bem como as secundárias que facilitarão o desenvolvimento e a explicação, de acordo com o conhecimento do expositor no assunto;

2) Mencionar o que sente dificuldade em recordar (datas, nomes, figuras) e utilizar abreviações habituais;

3) Fazer uso de gráficos e tabelas, somente se estes irão, realmente, ajudar no desenvolvimento do tema. Este recurso precisa ser legível e deve ser explicado pelo expositor, fazendo o público entender o que está sendo mostrado;

4) Adotar um padrão, isto é, usar um mesmo layout para os slides e um mesmo tipo de letra. É possível adotar uma formatação especial para títulos, outra para subtítulos e uma terceira para o texto propriamente dito. Adotar um padrão também para os recursos gráficos (diagramas, setas, conectores, entre outros).

A utilização do suporte é um meio de facilitar a comunicação oral, por isso alguns cuidados devem ser tomados para que a exposição seja eficiente. É preciso saber coordenar fala e material escrito, fazendo uso 
da mesma linguagem e evitar, somente, a leitura do que está escrito na projeção. Este é outro mau uso dos recursos, pois a audiência sabe ler, e muito bem. Ler o que está sendo projetado, além de tornar a apresentação cansativa, subestima as pessoas que estão assistindo à apresentação.

Juliana Bacan

Zani

Luzia Bueno

Joaquim Dolz

366

\section{Considerações Finais}

Uma formação acadêmica de qualidade exige um trabalho sobre os diferentes gêneros que caracterizam as práticas científicas e que permitem o seu desenvolvimento. A pesquisa é um instrumento primordial para a concepção de novos saberes dos ingressantes de nível superior. $E$, do ponto de vista interacionista, os gêneros da comunicação oral e escrita acadêmica são as ferramentas indispensáveis do trabalho científico para poder atuar como difusores do conhecimento.

Ampliar e compartilhar conhecimento e metodologias efetivas, além de melhorar as práticas educativas inerentes à formação universitária, é um desafio do sistema universitário brasileiro. A capacidade de produção, difusão e divulgação do conhecimento cientifico constitui um recurso qualificado para os cientistas. Nesse sentido, o domínio da "comunicação oral em eventos científicos" é uma garantia aos discentes de participarem da comunidade científica e difundir as novidades da cultura científica e tecnológica, resultado das pesquisas realizadas.

Concluindo o assunto abordado, a caracterização e a modelização didática desse gênero acadêmico oral e multimodal, baseado no quadro teórico metodológico do ISD, permite estabelecer uma matriz das dimensões regulares do gênero que merecem ser abordadas na formação universitária. A consideração e a antecipação do uso oral multimodal em eventos científicos tem um impacto para o conjunto de uma formação que busca implicar diretamente os estudantes universitários na construção e na difusão de saberes científicos.

Sendo assim, o modelo didático do gênero apresentado possibilita aos professores de nível superior desenvolverem atividades, sequências didáticas e itinerários de acompanhamento para que os novos acadêmicos consigam produzir e compartilhar conhecimentos científicos. Duas grandezas devem estar ligadas na formação acadêmica: a socialização do saber e a implicação dos educandos na pesquisa e produção do saber. Para poder associá-las e entrar na comunidade cientifica, o gênero comunicação oral em eventos científicos é indispensável. 


\section{REFERÊNCIAS}

BEHLAU, M.; PONTES, P. Avaliação e tratamento das disfonias. São Paulo: Lovise, 1995.

As dimensões

ensináveis

BRONCKART, J. P.. Atividade de linguagem, textos e discursos: do gênero por um interacionismo sociodiscursivo. $2^{\mathrm{a}}$ ed. Trad. Anna Rachel Machado. São Paulo, Educ, 1999/2009.

textual " $a$ comunicação oral em

DE PIETRO, J. F. Um modele didactique du 'débat': De l'objet social à la pratique scolaire. Enjeux, 39-40, pp. 110-129, 1996/1997.

eventos científicos"

DOLZ, J; GAGNON, R. O gênero de texto, uma ferramenta didática para desenvolver a linguagem oral e escrita. In: BUENO, L.; COSTA-HÜBES, T. C. (organizadoras). Gêneros orais no ensino. Campinas, SP: Mercado de Letras, 2015. (Série Ideias sobre Linguagem)

DOLZ, J.; SCHNEUWLY, B. Pour um ensignement de l'oral: initiation aux genres formels à l'école. Paris: ESF, 1998.

DOLZ, J.; SCHNEUWLY, B.; HALLER, S. O oral como texto: como construir um objeto de ensino. In: SCHNEUWLY, B.; DOLZ, J. Gêneros orais e escritos na escola. São Paulo: Mercado das Letras, 2004. p. $149-185$.

KNAPP, M. L. A comunicação não-verbal na interação humana. Tradução Mary Amazonas Leite de Barros. São Paulo:JNS Editora, 1999.

LEA, M. R.; STREET, B. V. O modelo de "letramentos acadêmicos": teoria e aplicações. Traduzido por: Fabiana Komesu e Adriana Fischer. São Paulo: Filol. Linguíst. Port. v. 16, n. 2, 477-493, jul/dez. 2014.

MACHADO, A. R.; CRISTOVÃO, V. L. L. A construção de modelos didáticos de gêneros: aportes e questionamentos para o ensino de gêneros. Revista Linguagem em (Dis)curso, volume 6, número especial, set./dez, 2006. 
MAGALHÃES, T. G. Oralidade e ensino de Língua Portuguesa no Brasil: uma leitura. In: MAGALHÃES, T. G. / CRISTÓVÃO, V. L. L. (Orgs.) Oralidade e ensino de Língua Portuguesa. Campinas, SP: Pontes Editores, 2018. OIDA, Y. O Ator invisível. São Paulo: Beca Produções Culturais, 2001.

Juliana Bacan

RABARDEL, P. Les activités avec instruments. Documento síntese Zani apresentado para habilitação à direção de pesquisas. Paris, Université Paris 8, 1993.

Luzia Bueno

Joaquim Dolz

RONVEAUX, C. Propédeutique à une didactique de l'oral: du rythme au dialogue intersémiotique. Enjeux, 39/40, 185-197, 1996/97.

368 SCHNEUWLY, B. Gêneros e tipos de discurso: considerações psicológicas e ontogenéticas. In: SCHNEUWLY, Bernard; DOLZ, Joaquim. Gêneros orais e escritos na escola. Trad. Roxane Rojo e Glaís Cordeiro. Campinas, SP: Mercado de Letras, 2004.

SCHNEUWLY, B; DOLZ, J. Gêneros orais e escritos na escola. Trad. Roxane Rojo e Glaís Cordeiro. Campinas, SP: Mercado de Letras, 2004.

VIGOTSKI, L. S. Pensée et Langage. Tradução Françoise Sève, Paris: La Dispute/SNÉDIT, 1934/1985.

WIRTHNER, M. Outils d'enseignement, au-delà de la baguette magique : outils transformateurs, outils transformés dans des séquences d'enseignement. Berne : Peter Lang, 2017.

ZANI, J. B.; BUENO, L. A arguição do candidato para qualificação ou defesa de mestrado e doutorado: um gênero oral a ser compreendido. VII - SIGET na terra de Iracema os gêneros textuais nas múltiplas esferas de atividade humana - Fortaleza - UECE/UFC, p. 1771-1783, 2013.

ZAVALA, V. Quem está dizendo isso? Letramento acadêmico, identidade e poder no ensino superior. In: VOVIO, C; SITO, L.; GRANDE, P. Letramentos. Campinas: Mercado de Letras, 2010. 